
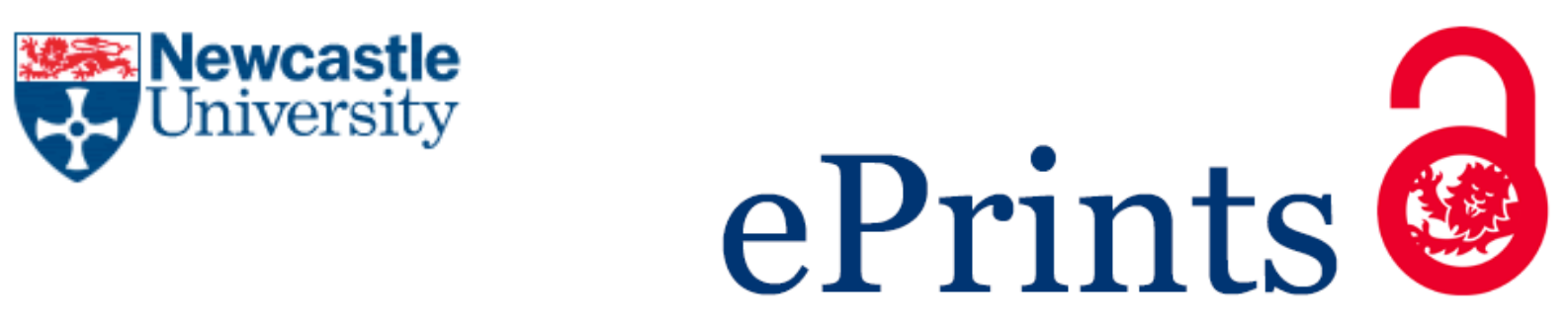

Elshahaly MH, Wheater G, Tuck SP, Datta HK, van Laar JM.

The role of B cells in bone turnover in rheumatoid arthritis. International Journal of Clinical Rheumatology 2012, 7(2), 167-177.

\title{
Copyright:
}

This is the authors' accepted manuscript of an article that has been published in its final definitive form by Future Medicine Ltd, 2012.

DOI link to article:

http://dx.doi.org/10.2217/ijr.12.5

Date deposited:

$20 / 09 / 2016$

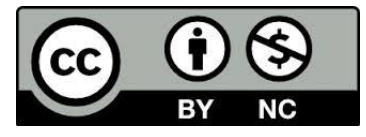

This work is licensed under a Creative Commons Attribution-NonCommercial 3.0 Unported License 


\section{The role of B cells in bone turnover in rheumatoid arthritis}

\section{Mohsen H Elshahaly}

Musculoskeletal Research Group, Institute of Cellular Medicine, 4th Floor Cookson Building, the Medical School, Framlington Place, Newcastle upon Tyne NE2 4HH

Phone: +44 (0)7429164010

Email: mohsen.elshahaly@newcastle.ac.uk

\section{Gillian Wheater}

Department of Biochemistry, The James Cook University Hospital, Middlesbrough, TS4 3BW

Phone: +44 (0)1642835870

Email: gill.wheater@stees.nhs.uk

\section{Stephen P Tuck}

Department of Rheumatology, The James Cook University Hospital, Middlesbrough, TS4 3BW Phone: +44 (0)1642854757

Email: stephen.tuck@stees.nhs.uk

\section{Harish K Datta}

Musculoskeletal Research Group, Institute of Cellular Medicine, 4th Floor Cookson Building, the Medical School, Framlington Place, Newcastle upon Tyne NE2 4HH

$\mathrm{Tel}+44(0) 1912226759$

Email: h.k.datta@newcastle.ac.uk

Jacob M van Laar

Musculoskeletal Research Group, Institute of Cellular Medicine, 4th Floor Cookson Building, the Medical School, Framlington Place, Newcastle upon Tyne NE2 4HH

$\mathrm{Tel}+44$ (0)1912223449

Email: j.m.van-laar@newcastle.ac.uk 


\section{Summary}

Recent research has focused on the connections between the immune and skeletal systems and a new discipline has emerged named osteoimmunology which incorporates the complex interactions and overlap between the two systems. The effect of B lymphocytes on bone metabolism is still poorly understood, although recent evidence suggests that B cells may particularly be implicated in the pathogenesis of bone loss in patients with rheumatoid arthritis (RA). Mature B cells have the potential to both inhibit and stimulate osteoclastogenesis via the secretion of specific cytokines; they have the ability to produce receptor activator of nuclear factor kappaB ligand (RANKL) a pro-osteoclastogenic cytokine, osteoprotegerin (OPG) an antiosteoclastogenic cytokine and transforming growth factor- $\beta$ (TGF- $\beta$ ) a cytokine that has the ability to both induce and inhibit osteoclast formation. It is therefore not surprising that the existing evidence from both in-vitro and in-vivo studies is inconsistent. This review critically examines the role of B lymphocytes and key cytokines in the regulation of osteoblasto- and osteoclastogenesis in RA.

Keywords: Osteoporosis, rheumatoid arthritis, B lymphocytes, bone turnover, B cell depletion, osteoclastogenesis. 


\section{Introduction}

Rheumatoid arthritis (RA) is a chronic, systemic, inflammatory autoimmune disease characterized by symmetrical polyarthritis, joint destruction and extra-articular manifestations which can affect many different organ systems including: blood, skin, eyes, kidneys, heart and lungs. RA affects approximately $0.5-1 \%$ of the adult population worldwide [1]. The incidence of RA in England alone is 26,000 new cases per year, while its prevalence is believed to be more than 690,000 patients, resulting in a total annual cost of almost eight billion pounds [2]. RA is characterized by increased morbidity and mortality with considerable reduction in quality of life. While there has been progress in defining the etiology and pathogenesis of RA these are still incompletely understood. There is synovial inflammation, subsequent pannus formation and intra-articular bone erosions, which results in structural damage and it is this joint damage that is the major reason for disability in RA patients. In addition, the disease can affect the whole musculoskeletal system including; bones, cartilage, ligaments and tendons. There is both localized, peri-articular bone loss as well as generalized bone loss. Osteoporosis is one of the leading morbidities of RA and approximately one third of women with RA will develop a fracture within 5 years of their diagnosis [3]. These data clearly show that bone loss in RA is a significant public health issue; this review will focus on the importance of B cells in RA and their effects on the associated bone loss.

B lymphocytes are typically characterized by their ability to produce antibodies, including autoantibodies. Since the discovery of rheumatoid factor (RF) and other citrullinated peptides, the role of B lymphocytes in RA has become more established and a number of treatments have 
been developed to specifically target B cells. Tumor necrosis factor alpha (TNF- $\alpha$ ) blocking agents were the first biological therapies to be approved for treating RA, however it is estimated that between 20 to 40 percent of patients fail to achieve a 20 percent improvement in the American College of Rheumatology (ACR) criteria. In addition, many patients lose response over time (secondary failure) and others develop side effects [4]. The relative success of specifically targeting TNF- $\alpha$ focused research into other components of the immune system in RA. Rituximab (RTX) is the first B cell targeted treatment originally used for the treatment of hematological malignancies such as lymphoma and leukemia. RTX is a chimeric monoclonal antibody directed against the CD20 molecule found on the surface of B cells, it depletes a large proportion of the $\mathrm{B}$ cell population with the exception of pro-B cells and mature plasma cells. RTX has proven to be highly successful and has renewed the interest in the role of B cells in RA [5]. Recent investigations have provided a great deal of evidence for a complex interaction between the immune and skeletal systems in physiological and pathological conditions. Results have shown that a number of cell surface receptors, cytokines and signaling pathways serve a critical role in both systems. In RA, the immune disturbance results in abnormal bone remodeling leading to bone loss. It is becoming clear that immune cells influence bone remodeling and vice versa. The interaction between immune progenitor cells and bone cells is facilitated by their proximity in the bone marrow where both osteoclastogenesis and hematopoiesis take place. The role of the immune system, especially $\mathrm{T}$ cells, in inflammatory bone resorption and osteoclastogenesis is well established [6]. In addition to the indirect effects on bone turnover through the production of inflammatory cytokines that modulate osteoclastogenesis, $\mathrm{T}$ cells may also regulate bone turnover through direct cell-cell interaction with bone cells. On the other hand, bone cells may influence the immune responses as well as 
accentuate bone turnover by affecting $\mathrm{T}$ cell activity through their ability to secrete different cytokines. Osteoclasts express major histocompatibility complex (MHC) class II molecules on their surface; they also activate $\mathrm{CD} 40 / \mathrm{CD} 40 \mathrm{~L}$ signaling which is essential for T-cell and macrophage activation and many B cell functions [7]. Additionally, osteoclasts release abundant $\mathrm{T}$ cell chemo-attractants and can alter $\mathrm{T}$ cell responses by different mechanisms including: decreasing their development, inhibiting cytokine production by $\mathrm{T}$ cells such as TNF- $\alpha$ and interferon-gamma (IFN- $\gamma$ ) and by regulating their apoptosis [8].

The role of B cells in bone turnover in RA is still controversial. However, recent work by our group has demonstrated decreased bone resorption and increased formation following treatment with RTX, suggesting that B-cells may also be important in regulating bone turnover [9]. Other components of the immune system such as cytokines also play a critical role in the pathogenesis of RA induced bone loss. The most important cytokines involved in the disturbed bone imbalance in RA are receptor activator of nuclear factor kappa B ligand (RANKL) and osteoprotegerin (OPG) [10].

\section{Overview of B cells}

B cell development

B cells are formed in the bone marrow where hematopoietic stem cells differentiate initially through the pro-B, pre-B cell stage and into immature B cells which then complete their maturation in the spleen through three developmental stages; transitional type 1; type 2; then mature B cells [11]. Mature B cells then differentiate into antibody secreting plasma cells and memory B cells, also known as effector B cells. B cells are subdivided into two main types; B1 
cells are characterized by expressing mainly immunoglobulin $\mathrm{M}(\operatorname{Ig} \mathrm{M})$ and present in low numbers in the lymph nodes and spleen and more abundantly in the peritoneal and pleural cavities; while B2 cells are present in the peripheral circulation and the bone marrow [12]. Recent studies also indicate the coexistence of a distinct B cell subset called B regulatory cells (Bregs), which suppress immune function.

\section{Regulation of B cell function}

B cell regulation in physiological and pathological conditions is a complex mechanism under the influence of many cells. T cells are thought to play a major role in the activation of B cells by two mechanisms. The first through direct cell to cell contact in which the primary signal is the B cell receptor (BCR) binding to antigen and then presenting the antigen via MHC class II to the $\mathrm{T}$ cell receptor (TCR) on the surface of T cells, these in turn provide the B cells with the secondary signal via co-stimulatory binding of CD40L on T cells to CD40 on B cells to complete the B cell activation. The antigen-presenting function of B lymphocytes is thought to be relevant mainly in the late phase of infections and in secondary immune responses, due to the low number of clonogenic antigen-specific B cells that are present in homeostatic conditions [13]. The second mechanism by which $\mathrm{T}$ cells regulate $\mathrm{B}$ cell activity is by the release of lymphokines acting as growth factors for B cells [14]. Additionally, many cytokines and transcription factors contribute to the regulation of B cell development and activity, summarized in Table 1.

\section{Regulation of B cell homeostasis by bone cells}

There is growing evidence for a role of bone cells in hematopoiesis. B lymphopoiesis is maintained by osteoblasts in the bone marrow by their ability to support the differentiation and 
proliferation of hematopoietic stem cells into all B cell stages. Culturing murine osteoblasts in vitro with primitive hematopoietic stem cells led to their differentiation into mature $\mathrm{B}$ lymphocytes. The authors showed that osteoblasts activated by PTH, stimulated B cell differentiation by signaling pathways that include vascular cell adhesion molecule 1 (VCAM-1), stromal cell-derived factor 1 (SDF-1) and IL-7. Furthermore, adding cytokines produced by stromal cells of non-osteoblastic origin such as c-Kit ligand, IL-6 and IL-3, led to myelopoiesis instead of lymphopoiesis [15]. Also, elimination of osteoblasts in vivo resulted in B cell depletion [16]. In a different murine model, blockade of osteoblastic PTH signaling by ablation of the G protein $\alpha$ subunit (Gs $\alpha$ ), a class of $\mathrm{G}$ proteins that activate phospholipase $\mathrm{C}$ and participate in a variety of cellular signaling pathways, led to marked decrease in the numbers of $\mathrm{B}$ cells in the bone marrow but not the other hematopoietic cells [17].

Osteoclast activity is suggested to also have a critical role in B cell development in the bone marrow. Evidence has been obtained through studies in osteopetrosis. In this genetic condition there is a failure of bone resorption by osteoclasts and increased bone density, however the bone structure is poor and there is a tendency to fracture. Osteopetrosis is also characterized by reduced numbers of B cells, whether this decrease in B cell numbers is due to impaired bone marrow architecture and abnormal microenvironment, or if this is a direct effect of the disturbed function of osteoclasts on B cells in the bone marrow is unknown. Reports from the literature suggest that interactions between B cell precursors and bone marrow stromal cells are essential for B cell differentiation, but the role of osteoclasts in this process remains controversial. Recently, a mice model injected with zoledronic acid, an anti-resorptive agent, to artificially induce osteopetrosis was used to clarify the link between osteoclastic activity and B cell 
development. The zoledronic acid led to suppression of osteoclastogenesis and a marked reduction in B cell numbers. The authors concluded that osteoclasts can modulate B-cell development in the bone marrow by controlling the bone microenvironment and the osteoblastic activity but they could not rule out the hypothesis that osteoclasts may directly affect B lymphopoiesis [18].

\section{Role of B cells in Rheumatoid Arthritis}

B cells have multiple functions in the pathogenesis of RA; they secrete auto-antibodies such as RF and the highly specific anti-cyclic citrullinated peptides antibodies (ACPA). RFs are antibodies directed against the Fc portion of IgG, along with ACPA they are thought to play a major role in the perpetuation of immune complexes suggested to be the main trigger for RA pathology. Additionally, B cells can process and present immune complexes and consequently activate complement thus contributing to autoimmune responses [19]. B cells are also able to secrete different pro-inflammatory cytokines and promote differentiation of follicular dendritic cells in secondary lymphoid organs [20]. In RA, effector B cells for example secrete TNF- $\alpha$, IL6 , IL-12 and IFN- $\gamma[21,22]$. TNF- $\alpha$ plays a critical role in the pathogenesis of RA and its inhibition is currently one of the most successful treatments available for this disease. TNF- $\alpha$ has a wide variety of functions including; complement activation and stimulation of synovial fibroblasts and macrophages to secrete pro-inflammatory cytokines such as IL-6, prostaglandin E2 (PGE2) and matrix metalloproteinases (MMPs) inducing inflammation, cartilage and bone damage, in addition to transforming growth factor-beta (TGF- $\beta$ ), granulocyte/monocyte-colony stimulating factor (GM-CSF) and other growth factors that induce neovascularization and promote pannus formation characteristic of RA [23, 24]. IL-6, another major pro-inflammatory 
mediator secreted by many cells including B cells, has a pivotal role in RA. IL-6 shares many effects with TNF- $\alpha$, including stimulation of neovascularization, promotion of acute phase response, infiltration of inflammatory cells, synovial hyperplasia and damage to cartilage and bone [25]. B cells also produce IL-12 which stimulates the release of IFN- $\gamma$ by T lymphocytes and natural killer (NK) cells and activates the $\mathrm{T}$ cell immune response leading to cellular infiltration, induction of inflammation, as well as cartilage and bone destruction [26]. IL-12 levels in serum and in synovium correlate with disease activity in RA revealing the definite role of this mediator in RA pathology [27]. On the other hand, IFN- $\gamma$ is found to have a dual action on chronic inflammation as it is capable of both inducing chronic inflammation and regulating immune responses [28].

Interestingly, B cells can also secrete anti-inflammatory mediators such as IL-4 and IL-13. IL-4 inhibits the activity of pro-inflammatory TNF- $\alpha$, IL-1, IL-11 and IL-6, in addition to upregulating the inhibitory mediator IL-1 receptor antagonist in RA [29]. IL-13, similar to IL-4, is capable of suppressing the inflammation in RA [30].

Recently, a new subtype of regulatory B lymphocytes known as Bregs has been reported to regulate the immune system by producing the inhibitory cytokine IL-10. IL-10, also known as human cytokine synthesis inhibitory factor (CSIF), has pleiotropic effects in immune-regulation and inflammation. It down-regulates the proliferative responses and pro-inflammatory cytokine production by $\mathrm{T}$ helper cells, MHC class II antigen expression and co-stimulatory molecules on macrophages. Moreover Bregs can promote differentiation of $\mathrm{T}$ cells into regulatory IL-10 producing $\mathrm{T}$ cells and hence permit vigorous immune suppression. Despite these anti- 
inflammatory effects, IL-10 has also been found to be an activator of B cell proliferation and antibody production. Moreover, Bregs were found to have other potential inhibitory mechanisms including secretion of the inhibitory cytokine TGF- $\beta$, interactions with Tregs and the production of regulatory antibodies [31].

\section{Pathogenesis of bone loss in RA}

RA predisposes to both localized and generalized bone loss and increased fracture risk. This bone loss is multi factorial. Some of the drugs used to treat the condition can themselves cause bone loss such as glucocorticoids. Corticosteroids have been considered the cornerstone of the treatment of RA and most of the autoimmune diseases. Long-term use of corticosteroids is an established cause of generalized bone loss in RA. Nowadays, corticosteroid use has been minimized with the tendency to more aggressive use of disease modifying drugs (DMARDs) and the development of biological therapy. RA can be significantly disabling leading to marked reduction in mobility and even loss of the patient's ability to feed themselves which results in disuse atrophy of the muscles and a consequent reduction in bone mass. Muscle atrophy and joint destruction will also increase falls risk. Inflammation and autoimmunity are the main mechanisms of osteoporosis in RA. Chronic systemic inflammation leads to generalized osteoporosis and localized inflammation with regional osteoporosis [32]. It was therefore presumed that treating inflammation would be sufficient to stop bone loss in RA, but this view is now thought too simplistic. 


\section{Role of cytokines}

It has been well established that RA leads to increased bone resorption, but it has more recently been demonstrated that there is also substantially reduced bone formation. The increased bone resorption in RA has been explained by the increased osteoclastic activity under the effect of various inflammatory cytokines. Both RANKL-dependent and -independent osteoclastogenesis pathways are thought to play a role in the increased bone turnover in RA. Overproduction of RANKL by a wide range of cells, including osteoblasts, endothelial cells, $\mathrm{T}$ cells and $\mathrm{B}$ cells is a characteristic feature of RA. RANKL binds to its receptor RANK on the osteoclasts activating their proliferation and stimulating osteoclastogenesis. Human studies have revealed that RANKL plays a crucial role in the pathogenesis of bony erosions and peri-articular osteoporosis in RA. Synovial levels of RANKL positively correlate with disease activity and bone resorption in RA patients. RANKL in synovium is thought to be mainly secreted by B cells, synovial fibroblasts and T cells $[33,34]$. Moreover, higher serum levels of RANKL were found in patients with high bone resorption markers and low bone mineral density of hips. Also, levels of serum RANKL were able to predict joint destruction [35]. In another recent study, it was suggested that both increased RANKL and decreased OPG in peripheral blood is the main mechanism of osteoporosis in RA [36]

Interestingly, many other cytokines such as TNF- $\alpha$, IL-1, IL-4, IL-6, IL-7, IL-10, IL-11, IL-12, IL-13, IL-17, IL-18, IFN- $\gamma$ and GM-CSF have variable effects on bone turnover and act via different mechanisms. TNF- $\alpha$ is a key player in RA osteoclastogenesis by both RANKLdependent and independent mechanisms. TNF- $\alpha$ blocking agents have recently been proven to 
reduce the local and generalized bone loss in RA [37]. Moreover, TNF- $\alpha$ is thought to inhibit bone formation by increasing dickkopf-related protein 1 (Dkk-1) expression leading to sequestration of low-density lipoprotein receptor-related protein 5 and 6 (LRP5 \& LRP6) receptors on the surface of osteoblasts; hence decreasing their binding to Wingless-Int (Wnt) proteins. Blocking the Wnt/beta-catenin signaling pathway leads to inhibition of osteoblasts differentiation and stimulation of their apoptosis resulting in decreased bone formation [38]. IL-1 is capable of increasing bone resorption by increasing the release of MMPs and other degradative products and by promoting osteoclast differentiation and activation [39]. IL-1 can stimulate bone cells to secrete RANKL, IL-6 and IL-11; it can also induce bone loss by a RANKL-independent mechanism [40]. Moreover, IL-1, TNF $\alpha$ and IFN- $\gamma$ can also suppress bone formation by inhibiting osteoblast collagen formation [41]. IL-6 induces osteoclastogenesis via the activation of T helper cells to secrete RANKL and IL-17 [42] and IL-17 is a major inducer of osteoclastic activity in inflammatory arthritis secreted by TH17 cells [43].

IFN- $\gamma$ functions as a modulator of bone turnover as it has a dual effect on osteoclasts; IFN- $\gamma$ can block the formation of osteoclasts directly by inhibiting the differentiation of osteoclast precursors, but can also stimulate osteoclastogenesis indirectly by activating $\mathrm{T}$ cells to produce RANKL and TNF- $\alpha$. It was presumed that the end function of IFN- $\gamma$ is the induction of bone loss [44]. However, recently IFN- $\gamma$ has been found to play a pivotal role in bone formation in vivo, IFN- $\gamma$ knockout mice developed osteoporosis and suffered from a marked decrease in both osteoblast and osteoclast numbers [45]. 
In contrast, other cytokines such as IL-4, IL-10, IL-12, IL-13, IL-18 and GM-CSF are protective of bone by either inhibiting osteoclastogenesis, or stimulating bone formation by osteoblasts. IL4 can suppress bone resorption and promote bone formation through its ability to inhibit the osteoclastogenic cytokines TNF- $\alpha$, IL-1, IL-6 and IL-11 in RA. Additionally IL-4 and IL-13 can stimulate osteoblasts and suppress prostaglandin E2 (PGE2) synthesis [46]. IL-10 is secreted by many cells, primarily monocytes and to a lesser extent by lymphocytes, and is known to have an immunoregulatory effect in RA. It is presumed that it may have an anabolic effect on bone turnover by decreasing the production of TNF- $\alpha$, IL-1, GM-CSF and the expression of HLA class II by monocytes [47]. Moreover, IL-10 is able to suppress the inflammatory effects of TH17 cells and promote the immunoregulatory Treg formation in RA patients resulting in the inhibition of osteoclast activity [48]. GM-CSF has been thought to inhibit osteoclast formation and activity; nevertheless the results of in vivo studies are conflicting [49]. IL-12 is capable of inhibiting osteoclastogenesis through its ability to stimulate immune cells particularly $\mathrm{T}$ cells and dendritic cells to secrete IFN- $\gamma$ [50]. IL-18 is capable of inhibiting osteoclast formation by the ability to stimulate the release of GM-CSF by T helper cells [51]. Additionally, it has recently been reported that IL-18 can inhibit TNF- $\alpha$ mediated osteoclastogenesis in vivo by a T cell independent mechanism [52].

On the other hand, decreased bone formation in RA has been suggested to be mainly due to increased expression of Dkk-1. In a mouse model of RA, inhibition of Dkk-1 by a neutralizing antibody led to a reversal of bone erosion and resulted in new bone formation although no change in markers of inflammation was noted [53]. 


\section{The role of $T$ cells}

$\mathrm{T}$ cells are involved in most of the autoimmune diseases including RA. For many decades RA was considered to be a T-cell dependent disease as evidenced by large numbers of $\mathrm{CD} 4^{+} \mathrm{T}$ cells infiltrating the synovial tissues of RA patients [54]. T cells are activated by antigen presenting cells and trigger the immune response by secreting a wide range of inflammatory cytokines and thereby activating the whole immune system. T cells are a major source of RANKL and TNF- $\alpha$ and are therefore capable of regulating bone turnover in RA by activating osteoclastogenesis [55]. On the other hand, $\mathrm{T}$ cells may have an inhibitory effect on osteoclastogenesis by increasing OPG production by a mechanism that involves increased vitamin D3 activity [56]. T helper1 (Th1) cells produce IFN- $\gamma$ and IL-2 and activate cell mediated immune response, whereas the T helper2 (Th2) subset produces IL-4 and stimulates humoral immunity. Imbalance between these two subsets results in inappropriate production of their respective cytokines and was found to be correlated with disease activity [57]. Despite the inflammatory effects of T cells in RA, there is also a protective subset named regulatory $\mathrm{T}$ cells (Tregs) which have antiinflammatory and bone protective effects. They act by regulating both type 1 and type 2 helper $\mathrm{T}$ cells [58]. Notably, both Tregs and $\mathrm{CD}^{+} \mathrm{T}$ cells have anti-osteoclastogenic effects [59]. However in RA it is still not established if there is a defect in the number or function of Tregs and whether this defect is directly related to RA osteoporosis. Interestingly, TNF- $\alpha$ has been found to suppress the Tregs response and this might be another mechanism by which TNF blocking agents act to control the disease activity and bone turnover in RA [60]. A third type of helper T cells, Th17 cells, has recently been implicated in RA bone loss. Th17 cells secrete IL-17 which is capable of inducing osteoclastogenesis resulting in bone damage [61]. Additionally, $\mathrm{T}$ 
cells are capable of interacting either directly with osteoblasts and osteoclasts or indirectly via stimulating dendritic cells and B cells [62].

\section{The role of $B$ cells in bone loss in RA}

Crosstalk between bone cells and B lymphocytes is bidirectional; bone cells can regulate the development and maturation of B cells and B cells can regulate both osteoblastic and osteoclastic activity. The mechanisms that underlie these interactions are only partially understood as is the precise role of B cells in bone turnover. B cells have the capacity to both stimulate and inhibit bone turnover by direct and indirect mechanisms (Figure 2). Additionally, B cells appear to be capable of affecting bone formation and resorption under different physiological and pathological conditions.

\section{$B$ cells and cytokines}

Mature B cells secrete a number of different cytokines; including RANKL a key cytokine involved in bone breakdown and its inhibitor OPG, this mechanism works correctly under normal physiological conditions. The bone protective role of B cells is mainly achieved through OPG production. In RA this balance is disturbed by the increased B and T cell activity, leading to a marked increase in the production of RANKL by both cells in addition to other proinflammatory cytokines such as TNF- $\alpha$. This shifts the bone turnover balance towards bone loss. In an RA human model, the cytokine messenger-RNA expression by CD4 and CD8 T cells, B cells, macrophages and neutrophils was evaluated to identify the source of RANKL in the 
synovial fluid and peripheral blood. B cells appeared to be a major source of RANKL in RA [33]. In addition to the bone specific cytokines mentioned above, other cytokines secreted by B cells can affect bone turnover and can either induce bone formation or bone resorption. TNF- $\alpha$ and IL-6 for example are pro-osteoclastogenic, while TGF- $\beta$, IL-4, IL-10, IL-12 and IL-13 are pro-bone formation. Additionally, B cells secrete IFN- $\gamma$ which has both bone resorption and bone formation effects. However, the net effect of these variable B cell cytokines seems to differ in physiological and different pathological conditions [63].

$B$ cells and osteoclasts

B cells are able to stimulate, both directly and indirectly, the conversion of monocytes to active osteoclasts. More interestingly, studies have shown that osteoclasts and B-lymphocytes may both arise from pro-B cells. Pro-B cells from osteopetrotic mice for example, expressed markers from the B-lymphoid (CD19, CD43 and CD5) and the myeloid (F4/80) lineages. When stimulated with RANKL and M-CSF, these cells could grow into osteoclasts, while they were able to differentiate into B cells when stimulated by IL-7 [64]. Furthermore, B cells have been found capable of transforming into osteoclasts. Recently it has been found in a murine model that a subset of $\mathrm{CD} 19^{+} \mathrm{B}$ lymphocytes named B1 cells, can differentiate into mononuclear phagocytes forming osteoclast-like multinucleated giant cells. These cells express RANK and the macrophage colony-stimulating factor receptor (M-CSFR) and when stimulated with RANKL and M-CSF, these cells transformed into tartrate resistant acid phosphatase (TRAP) positive osteoclasts and have osteoclastic properties leading to the formation of lacunae when allowed to grow on a calcium phosphate analog. Deficiency of B1 cells in these mice resulted in failure of bone resorption. Moreover, reconstitution of these cells resulted in an increase of 
osteoclastogenesis [65]. In a human model of multiple myeloma, nuclei of malignant B cells were found in osteoclasts which might suggest that myeloma cells can differentiate into osteoclasts explaining the mechanism of increased osteoclastogenesis in these patients [66]. Additionally, deletion of any of the transcription factors Ebf-1, paired box protein 5 (Pax5) and PU.1, which are essential for B cell development, resulted in marked changes in bone turnover in vivo. The transcription factor PU.1 is a protein encoded by the SPI1 gene; it is a specific factor for gene expression during myeloid and B-lymphoid cell development. Levels of PU.1 positively correlated with osteoclastic differentiation in vitro and deletion of PU.1 in vivo led to the arrest of osteoclast and macrophage differentiation [67]. More recently, reduction in PU.1 activity resulted in impaired B-cell development [68]. Ebf-1 deficiency in mice, another key regulator of B cell development, led to increased osteoclastogenesis and impaired B cell development, but despite this there was an overall increased bone mass. The authors explained that the mechanism of increased bone balance was the concomitant increase in the numbers and activity of osteoblasts. However, there is a hypothesis that B cell depletion may share in this anabolic effect on bone [69].

\section{Effect of B cell deficiency on bone}

It appears that too few B-cells can also be a problem and may result in bone loss. For example, in one murine model B cell deficiency resulted in marked osteopenia, this was explained by the resulting decrease in the amount of OPG that would have been produced by B cells. In a different study, PAX5 deficient mice showed a loss of B cells and increased bone turnover from a dramatic rise in the numbers of osteoclasts together with a mild reduction in osteoblast numbers. The result was a marked decrease in bone volume, specifically trabecular bone. 
However, they could not explain whether the resulting osteopenia was due to the decreased osteoblastic activity or the increased osteoclastogenesis or a combination of both [70].

\section{New clinical evidence}

Data generated by our group demonstrated significant changes in bone turnover following B-cell depletion with RTX in RA patients, namely a decrease in bone resorption as evidenced by a marked decrease in beta-crosslaps $(\beta \mathrm{CTx})$ and an increase in bone formation demonstrated by a rise in procollagen type 1 amino-terminal propeptide (P1NP). This suggests that there was a positive effect on bone metabolism as a result of B cell depletion therapy, which might result in an improvement in bone density and decreased fracture risk in RA patients. This effect may be due to remission of the disease activity, a reduction of the inflammatory process, improved general condition and therefore increased physical activity or may be due to a direct antiresorptive effect of the $\mathrm{B}$ cell depletion on bone cells or indeed a combination of all of these factors [9]. Further studies on larger cohorts are required to determine the exact mechanism of how B cells affect bone turnover.

\section{Future perspective}

The B cell is a tempting target for the treatment of bone loss mediated by RA. Future research will explore the underlying mechanisms of how B cells affect bone metabolism, this is critical for preventing and treating osteoporosis induced by RA. This knowledge may be a useful indicator of future disease course and have the potential to give clinicians valuable information about an individual patient's response to treatment. Such understanding may also give insights into the pathophysiology of osteoporosis and other metabolic bone disorders. 


\section{Financial and competing interest's disclosure}

JMvL has received a research grant, consultancy and speaker fees from Roche. SPT has received speaker fees from Ely Lilly. Roche is not financing this manuscript.

No writing assistance was utilized in the production of this manuscript. 


\section{Key Issues}

\section{Rheumatoid arthritis definition and epidemiology}

- RA is a chronic, systemic, inflammatory autoimmune disease characterized by symmetrical polyarthritis, joint destruction and extra-articular manifestations.

- Joint damage contributes to disability in RA and the associated life time treatment costs and loss of productivity represent a substantial economic burden.

Interaction between the immune and skeletal systems

- The interaction between the immune cells and bone cells is complex. This might include direct cross talking through their proximity in the bone marrow as well as indirect signals via different cytokines.

\section{Overview of B cells in RA}

- B cells develop in the bone marrow from haematopoietic stem cells.

- B cells play a critical role in the pathogenesis of RA by various mechanisms.

- B cell regulation is complex and under the influence of many cells, cytokines and other factors.

\section{Pathogenesis of bone loss in RA}

- RA induced osteoporosis is multi factorial with various components of the immune system participating in its pathogenesis including cytokines, $T$ cells and $B$ cells.

\section{The role of $B$ cells in bone loss in RA}

- Crosstalk between bone cells and B lymphocytes is bidirectional.

- B-lymphocytes have the capacity to both inhibit and stimulate osteoclastogenesis by different mechanisms.

- RANKL and OPG remain the key players in the pathogenesis of osteoporosis in RA but other mediators and cells may also be involved.

- B lymphocytes have a role in bone formation in addition to bone resorption.

- B cells have a significant effect on bone turnover but whether the net effect is towards formation or resorption is still controversial and may well depend on the circumstances.

- $\quad$ B cell depletion therapies may have a beneficial effect on bone loss. 


\begin{tabular}{|c|c|}
\hline Factor & Effect \\
\hline $\begin{array}{l}\text { BAFF (B lymphocyte stimulator } \\
\text { (BLyS)) }\end{array}$ & $\begin{array}{l}\text { Protein belonging to the TNF superfamily that activates B } \\
\text { cell differentiation; was found higher in RA compared to } \\
\text { controls [71] }\end{array}$ \\
\hline APRIL & $\begin{array}{l}\text { Activator of B cell differentiation that has been found } \\
\text { higher in RA compared to controls [71] }\end{array}$ \\
\hline Bruton's tyrosine kinase (Btk) & $\begin{array}{l}\text { Activator of B cell differentiation; Its absence led to } \\
\text { impaired B cell responses and reduced immunoglobulin } \\
\text { levels [72] }\end{array}$ \\
\hline RANK & $\begin{array}{l}\text { Essential for B cell maturation and development; Its } \\
\text { deficiency in mice resulted in failed B cell maturation [73] }\end{array}$ \\
\hline IL-7 & $\begin{array}{l}\text { Essential cytokine for B cell development; Its deficiency } \\
\text { leads to blockade of the transition between the Ly6D- and } \\
\text { the Ly6D+ stages of B cell development [74] }\end{array}$ \\
\hline $\begin{array}{l}\text { Neurotransmitter receptors } \\
\text { (dopamine receptor } 2 \text { and } \\
\text { acetylcholine receptor) }\end{array}$ & $\begin{array}{l}\text { Essential components for B cell development and were } \\
\text { found to be over expressed in RA B cells compared to } \\
\text { healthy individuals [75] }\end{array}$ \\
\hline Early B cell factor-1 (EBF-1) & $\begin{array}{l}\text { Protein needed for early B cell development that determines } \\
\text { the subset fate of early B cells; Its deficiency led to arrested } \\
\text { B cell development and maturation [76] }\end{array}$ \\
\hline Paired box protein (PAX5) & $\begin{array}{l}\text { Essential protein for B cell differentiation; Its deficiency } \\
\text { led to arrested B cell development and maturation [77] }\end{array}$ \\
\hline PU.1 & $\begin{array}{l}\text { A member of the ETS domain transcription factors that } \\
\text { regulate the development of B lineage cells; Its deficiency } \\
\text { impedes B cell proliferation [78] }\end{array}$ \\
\hline Ikaros family zinc protein 1 & $\begin{array}{l}\text { Transcription factor encoded by the Ikaros gene (Ikzf1); Its } \\
\text { deficiency led to a complete failure of B cell development } \\
\text { [79] }\end{array}$ \\
\hline
\end{tabular}




\section{Figure 1: Effect of $B$ cells on bone cells}

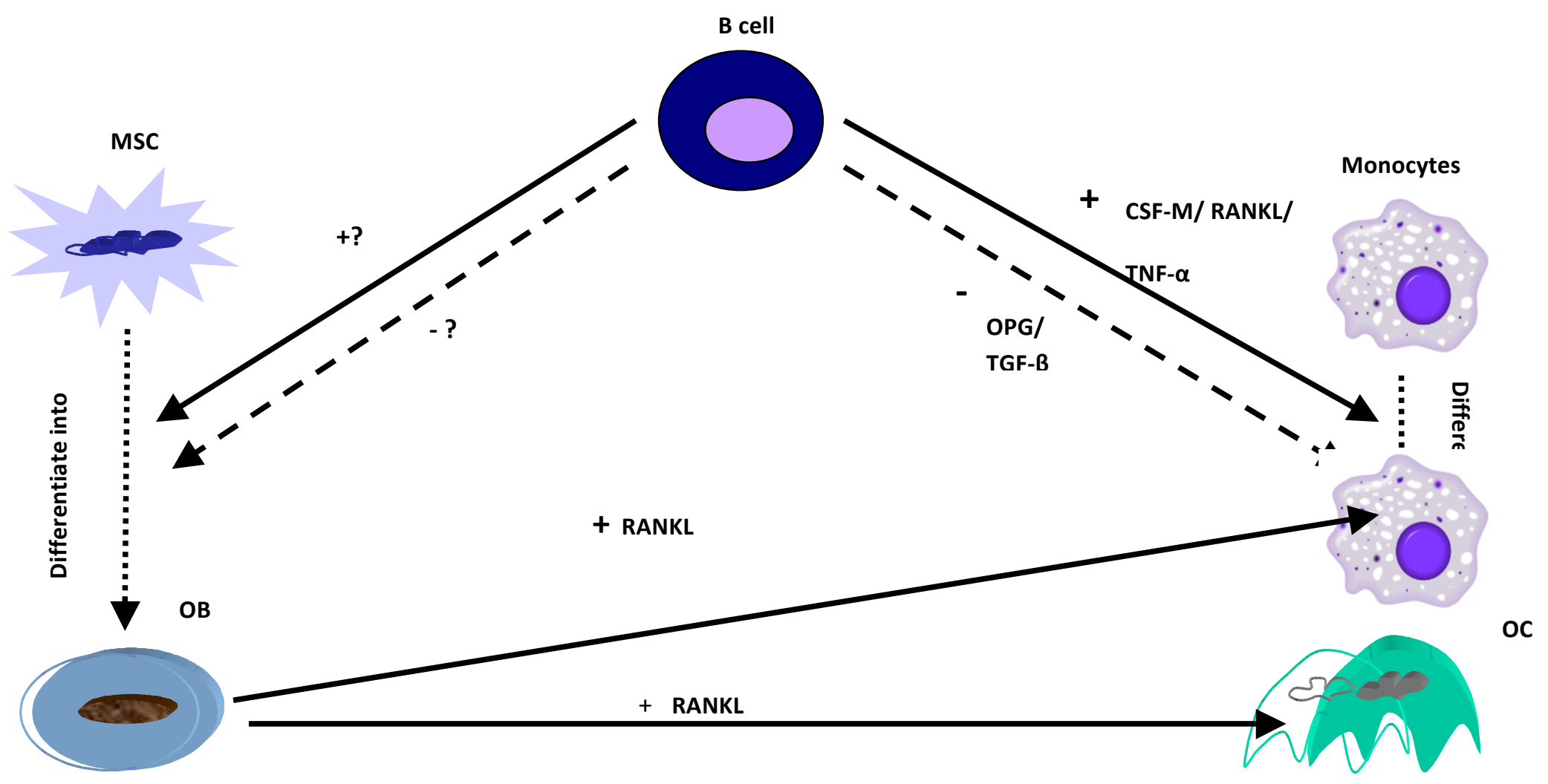

Stimulatory signal

Inhibitory signal

$---\longrightarrow$

Differentiate into

OB osteoblast, OC osteoclast, MSC mesenchymal stromal cell, RANKL receptor activator of nuclear factor kappaB ligand, OPG osteoprotegerin, TGF- $\beta$ transforming growth factor-beta, TNF- $\alpha$ tumour necrosis factor- alpha. 


\section{$\underline{\text { References }}$}

1- Kvien TK, Glennas A, Knudsrod OG, Smedstad LM, Mowinckel P, Førre O. The prevalence and severity of rheumatoid arthritis in Oslo. Results from a county register and a population survey. Scand. J. Rheumatol. 26(6), 412-418 (1997).

2- Von Radowitz J. Rheumatoid arthritis 'costs up to $£ 8$ bn a year'. The independent health news 1931969 (2010).

3- Michel BA, Bloch DA, Fries JF. Predictors of fractures in early rheumatoid arthritis. J. of Rheumatology 18(6), 804-808 (1991).

4- Rubbert-Roth A and Finckh A. Treatment options in patients with rheumatoid arthritis failing initial TNF inhibitor therapy: a critical review. Arthritis Res Ther. 11(Suppl 1), S1 (2009).

5- Edwards J, Szczepanski L, Szechinski J, et al. Efficacy of B-cell-targeted therapy with rituximab in patients with rheumatoid arthritis. N Engl J Med 350 (25), 2572-81 (2004)

6- Li Y, Toraldo G, Li A, et al. B cells and T cells are critical for the preservation of bone homeostasis and attainment of peak bone mass in vivo. Blood 109(9), 3839-48 (2007).

7- Grewal IS, Flavell RA. The role of CD40 ligand in costimulation and T-cell activation. Immunol Rev 153, 85-106 (1996).

8- Grassi F, Manferdini C, Cattini L et al. T cell suppression by osteoclasts in vitro. J. of Cell Physiology, 226 (4), 982-990 (2011).

9- Wheater G, Hogan V, Teng Y, et al. Suppression of bone turnover by B-cell depletion in patients with rheumatoid arthritis. Osteoporos Int. (2011). E pub. ahead of print. **

This study represents the first proof of the beneficial effect of $B$ cells on bone turnover in humans.

10- Xu S, Wang Y, Lu J, Xu J. Osteoprotegerin and RANKL in the pathogenesis of rheumatoid arthritis-induced osteoporosis. Rheumatol Int. (2011). Epub ahead of print.

11-Loder F, Mutschler B, Ray RJ, et al. B Cell Development in the Spleen Takes Place in Discrete Steps and Is Determined by the Quality of B Cell Receptor-Derived Signals. $J$. Exp. Med. 190(1), 75-89 (1999).

12- James T and Herzenberg L. Unraveling B-1 progenitors. Curr Opin Immunol. 19(2), 150155 (2007). 
13- Morlacchi S, Soldani C, Viola A, Sarukhan A. Self-antigen presentation by mouse B cells results in regulatory T-cell induction rather than anergy or clonal deletion. Blood 118(4):984-91. (2011).

14- Sakaguchi S, Ono M, Setoguchi R, et al. Foxp3+ CD25+CD4+ natural regulatory T cells in dominant self-tolerance and autoimmune disease. Immunol. Rev. 212, 8-27 (2006).

15-Martinez-Gamboa L, Brezinschek HP, Burmester GR, Dörner T. Immunopathologic role of B lymphocytes in rheumatoid arthritis: Rationale of B cell-directed therapy. Autoimmun Rev. 5(7), 437-442 (2006).

16-Zhu J, Garrett R, Jung Y, et al. Osteoblasts support B-lymphocyte commitment and differentiation from hematopoietic stem cells. Blood 109(9), 3706-12 (2007)

17- Wu JY, Purton LE, Rodda SJ, et al. Osteoblastic regulation of B lymphopoiesis is mediated by Gs $\alpha$-dependent signaling pathways. Proc Natl Acad Sci USA, 105(44), 16976-81 (2008).

18-Mansour A, Anginot A, Mancini SJ, et al. Osteoclast activity modulates B-cell development in the bone marrow. Cell Res., 21(7), 1102-15 (2011). *

This study demonstrated the crosstalk between osteoclasts and B cells in the bone marrow.

19- Yan J, Harvey BP, Gee RJ, Shlomchik MJ, Mamula MJ. B cells drive early T cell autoimmunity in vivo prior to dendritic cell-mediated autoantigen presentation. $J$ Immunol 177(7), 4481-4487 (2006).

20-Randall TD, Carragher DM, Rangel-Moreno J. Development of secondary lymphoid organs. Annu Rev Immunol. 26:627-50 (2008).

21-Hirano T, Matsuda T, Turner M, e $t$ al. E xcessive production of interleukin 6/B cell stimulatory factor-2 in rheumatoid arthritis. Eur J Immunol 18(11):1797-801 (1988).

22-Harris DP, Haynes L, Sayles PC, et al. Reciprocal regulation of polarized cytokine production by effector B and T cells. Nat Immunol 1(6), 475-482 (2000).

23-Bhardwaj N, Santhanam U, Lau LL, et al. IL-6/IFN beta 2 in synovial effusions of patients with rheumatoid arthritis and arthritides. Identification of several isoforms and studies of cellular sources. J Immunol 143, 2153-2159 (1989).

24- MacNaul KL, Chartrain N, Lark M, et al: Discoordinate expression of stromelysin, collagenase, and tissue inhibitor of stromelysin, collagenase, and tissue inhibitor of metalloproteinases-1 in rheumatoid human synovial fibroblasts. Synergistic effects of 
interleukin-I and tumor necrosis factor-alpha on stromelysin expression. J Biol Chem 265(28):17238-45 (1990).

25-Hashizume M, Mihara M. The roles of interleukin-6 in the pathogenesis of rheumatoid arthritis. Arthritis 765624. (2011).

26- Paunovic V, Carroll HP, Vandenbroeck K, Gadina M. Signalling, inflammation and arthritis: crossed signals: the role of interleukin (IL)-12, $-17,-23$ and -27 in autoimmunity. Rheumatology (Oxford) 47(6), 771-6. (2008).

27-Kim W, Min S, Cho M, et al. The role of IL-12 in inflammatory activity of patients with rheumatoid arthritis (RA). Clin Exp Immunol 119, 175-81 (2000).

28- Irmler I, Bräuer R. Paradoxical role of interferon-gamma in arthritis. Z Rheumatol. 66(7), 591-2, 594 (2007).

29-Miossec P, Briolay J, Dechanet J, Wijdenes J, Martinez-Valdez H, Banchereau J. Inhibition of the production of proinflammatory cytokines and immunoglobulins by interleukin-4 in an ex vivo model of rheumatoid synovitis. Arthritis Rheum. 35(8), 87483 (1992).

30-Radstake TR, Nabbe KC, Wenink MH, et al. Dendritic cells from patients with rheumatoid arthritis lack the interleukin 13 mediated increase of Fc gamma RII expression, which has clear functional consequences. Ann Rheum Dis. 64(12), 1737-43 (2005).

31-Klinker MW, Lundy SK. Multiple Mechanisms of Immune Suppression by B Lymphocytes. Mol Med. (2011) [Epub ahead of print]. *

This study revealed the mechanisms of action of Bregs in regulation of the immune system.

32- Roux C. Osteoporosis in inflammatory joint diseases. Osteoporos Int. 22(2), 421-33 (2011).

33- Yeo L, Toellner KM, Salmon M, et al. Cytokine mRNA profiling identifies B cells as a major source of RANKL in rheumatoid arthritis. Ann Rheum Dis. 70(11), 2022-8 (2011).

**

This study showed that B cells are the major source of RANKL and consequently the main drivers of osteoclastogenesis.

34- Crotti TN, Smith MD, Weedon H, et al. Receptor activator NF-kB ligand (RANKL) expression in synovial tissue from patients with rheumatoid arthritis, 
spondyloarthropathy, osteoarthritis and from normal patient; semiquantitative and quantitative analysis. Ann. Rheum. Dis. 61, 1047-1054 (2002).

35-Geusens PP, Landewé RB, Garnero P, et al. The ratio of circulating osteoprotegerin to RANKL in early rheumatoid arthritis predicts later joint destruction. Arthritis Rheum. 54(6), 1772-7 (2006).

36- Xu S, Wang Y, Lu J. Osteoprotegerin and RANKL in the pathogenesis of rheumatoid arthritis-induced osteoporosis. Rheumatol Int. (2011) [Epub ahead of print]

37-Chopin F, Garnero P, le Henanff A, et al. Long term effects of infliximab on bone and cartilage turnover markers in patients with rheumatoid arthritis. Ann Rheum Dis. 67(3), 353-57 (2008).

38- Jilka RL, Weinstein RS, Bellido T, Parfitt AM, Manolagas SC. Osteoblast programmed cell death (apoptosis): modulation by growth factors and cytokines. J Bone Miner Res. 13(5), 793-802 (1998).

39- Abramson SB and Amin A. Blocking the effects of IL-1 in rheumatoid arthritis protects bone and cartilage. Rheumatology (Oxford) 41(9), 972-80 (2002).

40- Kudo O, Sabokbar A, Pocock A, Itonaga I, Fujikawa Y, Athanasou NA. Interleukin-6 and interleukin-11 support human osteoclast formation by a RANKL-independent mechanism. Bone 32(1), 1-7 (2003).

41-Centrella M, McCarthy TL, Canalis E. Tumor necrosis factor- $\alpha$ inhibits collagen synthesis and alkaline phosphatase activity independently of its effect on deoxyribonucleic acid synthesis in osteoblast-enriched bone cell cultures. Endocrinology 123(3), 1442-1448 (1988).

42-Wong PK, Quinn JM, Sims NA, et al. Interleukin-6 modulates production of T lymphocyte-derived cytokines in antigen-induced arthritis and drives inflammationinduced osteoclastogenesis. Arthritis Rheum. 54, 158-68 (2006)

43- Bettelli E, Carrier Y, Gao W, et al. Reciprocal developmental pathways for the generation of pathogenic effector TH17 and regulatory T cells. Nature 441, 235-8 (2006).

44-Gao Y, Grassi F, Ryan MR, et al. IFN-gamma stimulates osteoclast formation and bone loss in vivo via antigen-driven T cell activation. J Clin Invest. 117(1), 122-32 (2007).

45- Duque G, Huang DC, Dion N, et al. Interferon- $\gamma$ plays a role in bone formation in vivo and rescues osteoporosis in ovariectomized mice. J Bone Miner Res. 26(7), 1472-83 (2011). 
46- Onoe Y, Miyaura C, Kaminakayashiki T, et al. IL-13 and IL-4 inhibit bone resorption by suppressing cyclooxygenase-2-dependent prostaglandin synthesis in osteoblasts. $J$ Immunol. 156(2), 758-764 (1996).

47- Katsikis PD, Chu CQ, Brennan FM, Maini RN, Feldmann M. Immunoregulatory role of interleukin 10 in rheumatoid arthritis. J Exp Med. 179(5), 1517-27 (1994).

48- Heo YJ, Joo YB, Oh HJ, et al. IL-10 suppresses Th17 cells and promotes regulatory T cells in the CD4+ T cell population of rheumatoid arthritis patients. Immunology Letters 127(2), 150-6 (2010).

49- Hodge JM, Kirkland MA, Aitken CJ, et al. Osteoclastic potential of human CFU-GM: biphasic effect of GM-CSF. J Bone Miner Res. 19(2), 190-9 (2004).

50- Ohteki, T, Fukao T, Suzue K, et al. IL-12-dependent INF- $\gamma$ production by CD8a1 lymphoid dendritic cells. J. Exp. Med. 189(12):1981-6 (1999).

51- Horwood NJ, Elliott J, Martin TJ, Gillespie MT. IL-12 alone and in synergy with IL-18 inhibits osteoclast formation in vitro. J Immunol. 166(8), 4915-21 (2001).

52- Morita Y, Kitaura H, Yoshimatsu M, et al. IL-18 inhibits TNF-alpha-induced osteoclastogenesis possibly via a T cell-independent mechanism in synergy with IL-12 in vivo. Calcif Tissue Int. 86(3), 242-8 (2010).

53- Diarra D, Stolina M, Polzer K, Et al. Dickkopf-1 is a master regulator of joint remodeling Nat. Med. 13, 156 (2007). *

This study demonstrated that DKK-1 is the main inhibitor of the Wnt signaling pathway and bone formation.

54- Matsuoka N, Eguchi K, Kawakami A, et al. Phenotypic characteristics of $\mathrm{T}$ cells interacted with synovial cells. J. Rheumatol. 18(8), 1137-1142 (1991).

55- Kong YY, Feige U, Sarosi I, et al. Activated T cells regulate bone loss and joint destruction in adjuvant arthritis through osteoprotegerin ligand. Nature 402(6759), 304-9 (1999).

56- Grcevic D, Lee SK, Marusic A, Lorenzo JA. Depletion of CD4+ and CD8+ T lymphocytes in mice in vivo enhances 1,25- dihydroxyvitamin D3- stimulated osteoclastlike cell formation in vitro by a mechanism that is dependent on prostaglandin synthesis. J Immunol. 165(8), 4231-4238 (2000).

57- Abbas AK, Murphy KM, Sher A. Functional diversity of helper T lymphocytes. Nature 383(6603), 787-793 (1996). 
58- Yudoh K, Matsuno H, Nakazawa F, Yonezawa T, Kimura T. Reduced expression of the regulatory CD4+ $\mathrm{T}$ cell subset is related to $\mathrm{Th} 1 / \mathrm{Th} 2$ balance and disease severity in rheumatoid arthritis. Arthritis Rheum. 43(3), 617-627 (2000).

59- Choi Y, Woo KM, Ko SH, et al. Osteoclastogenesis is enhanced by activated B cells but suppressed by activated CD8 T cells. Eur J Immunol. 31(7), 2179-2188 (2001). *

The study was one of the first to demonstrate that B cells stimulate bone resoprtion.

60- van Amelsfort JM, van Roon JA, Noordegraaf M, et al. Proinflammatory mediatorinduced reversal of $\mathrm{CD}^{+}, \mathrm{CD} 25^{+}$regulatory $\mathrm{T}$ cell-mediated suppression in rheumatoid arthritis. Arthritis Rheum. 56(3), 732-742 (2007).

61- Sato K, Suematsu A, Okamoto K, et al. Th17 functions as an osteoclastogenic helper T cell subset that links T cell activation and bone destruction. J Exp Med 203(12), 2673-82 (2006).

62- Choi Y, Kim J. B cells activated in the presence of Th1 cytokines inhibit osteoclastogenesis. Exp Mol Med 35(5), 385-92 (2003).

63- Lund FE. Cytokine-producing B lymphocytes-key regulators of immunity. Curr Opin Immunol. 20(3):332-8 (2008). **

This article analyzed the different cytokines secreted by B lymphocytes.

64- Blin-Wakkach C, Wakkach A, Rochet N, Carle GF. Characterization of a novel bipotent hematopoietic progenitor population in normal and osteopetrotic mice. J Bone Miner Res. 19(7), 1137-43 (2004).

65- Pugliese LS, Gonçalves TO, Popi AF, Mariano M, Pesquero JB, Lopes JD. B-1 lymphocytes differentiate into functional osteoclast-like cells. Immunobiology (2011) [Epub ahead of print].

66- Andersen TL, Boissy P, Sondergaard TE, et al. Osteoclast nuclei of myeloma patients show chromosome translocations specific for the myeloma cell clone: a new type of cancer-host partnership? J Pathol. 211(1), 10-17 (2007).

67- Tondravi MM, McKercher SR, Anderson K, et al. Osteopetrosis in mice lacking haematopoietic transcription factor PU.1. Nature 386(6620), 81-84 (1997).

68- Houston IB, Kamath MB, Schweitzer BL, Chlon TM, DeKoter RP. Reduction in PU.1 activity results in a block to B-cell development, abnormal myeloid proliferation, and neonatal lethality. Exp Hematol. 35(7), 1056-68 (2007).

69- Horowitz MC and Lorenzo JA. B Lymphocytes and the skeleton. Ann NY Acad Sci. 1117, 82-93 (2007). 
70- Horowitz MC, Xi Y, Pflugh DL, et al. Pax5-deficient mice exhibit early onset osteopenia with increased osteoclast progenitors. J Immunol. 173(11), 6583-6591 (2004).

71- Moura RA, Cascão R, Perpétuo I, et al. Cytokine pattern in very early rheumatoid arthritis favours B-cell activation and survival. Rheumatology (Oxford) 50(2):278-82 (2011).

72- Khan WN, Alt FW, Gerstein RM, et al. Defective B cell development and function in Btk-deficient mice. Immunity 3(3):283-99 (1995).

73- Dougall WC, Glaccum M, Charrier K, et al. RANK is essential for osteoclast and lymph node development. Genes Dev. 13(18):2412-24 (1999).

74- Tsapogas P, Zandi S, Åhsberg J, et al. IL-7 mediates Ebf-1-dependent lineage restriction in early lymphoid progenitors. Blood 118(5), 332189 (2011).

75- Szodoray P, Alex P, Frank MB, et al. A genome- scale assessment of peripheral blood Bcell molecular homeostasis in patients with rheumatoid arthritis. Rheumatology (Oxford) 45(12), 1466-76 (2006).

76- Lin H, Grosschedl R. Failure of B-cell differentiation in mice lacking the transcription factor EBF. Nature 376(6537), 263-267 (1995).

77- Medvedovic J, Ebert A, Tagoh H, Busslinger M. Pax5 a master regulator of B cell development and leukemogenesis. Adv Immunol. 111, 179-206 (2011).

78- Tondravi MM, McKercher SR, Anderson K, et al. Osteopetrosis in mice lacking haematopoietic transcription factor PU.1. Nature 386(6620), 81-84 (1997).

79- Wang JH, Nichogiannopoulou A, Wu L, et al. Selective defects in the development of the fetal and adult lymphoid system in mice with an Ikaros null mutation. Immunity 5(6), 537-49 (1996). 